\title{
Overview of the TurbSim Stochastic Inflow Turbulence Simulator
}

\section{Version 1.21}

(Revised February 1, 2007)

N.D. Kelley and B.J. Jonkman

Technical Report NREL/TP-500-41137 April 2007

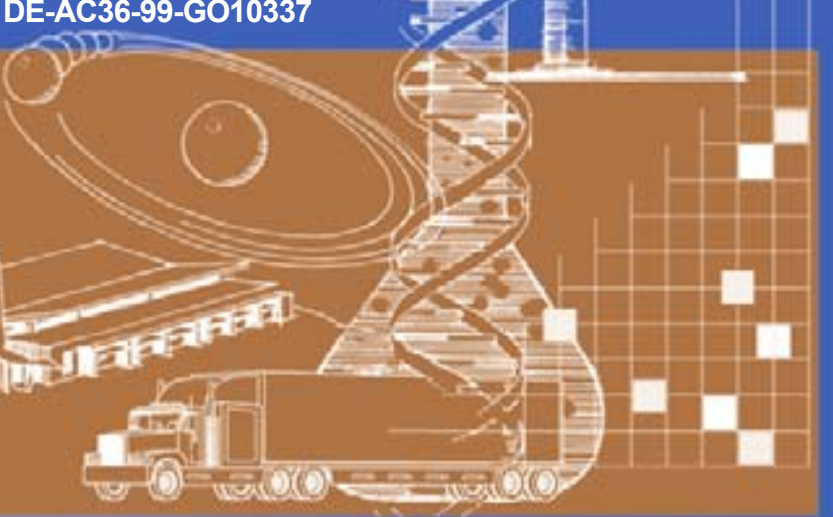




\section{Overview of the TurbSim Stochastic Inflow Turbulence Simulator}

\section{Version 1.21}

(Revised February 1, 2007)

N.D. Kelley and B.J. Jonkman

Prepared under Task No. WER7.2501
Technical Report NREL/TP-500-41137 April 2007

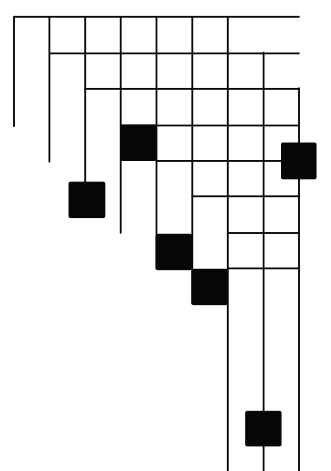




\section{NOTICE}

This report was prepared as an account of work sponsored by an agency of the United States government. Neither the United States government nor any agency thereof, nor any of their employees, makes any warranty, express or implied, or assumes any legal liability or responsibility for the accuracy, completeness, or usefulness of any information, apparatus, product, or process disclosed, or represents that its use would not infringe privately owned rights. Reference herein to any specific commercial product, process, or service by trade name, trademark, manufacturer, or otherwise does not necessarily constitute or imply its endorsement, recommendation, or favoring by the United States government or any agency thereof. The views and opinions of authors expressed herein do not necessarily state or reflect those of the United States government or any agency thereof.

Available electronically at http://www.osti.gov/bridge

Available for a processing fee to U.S. Department of Energy and its contractors, in paper, from:

U.S. Department of Energy

Office of Scientific and Technical Information

P.O. Box 62

Oak Ridge, TN 37831-0062

phone: 865.576 .8401

fax: 865.576 .5728

email: mailto:reports@adonis.osti.gov

Available for sale to the public, in paper, from:

U.S. Department of Commerce

National Technical Information Service

5285 Port Royal Road

Springfield, VA 22161

phone: 800.553.6847

fax: 703.605.6900

email: orders@ntis.fedworld.gov

online ordering: http://www.ntis.gov/ordering.htm 


\section{OVERVIEW OF THE TURBSIM STOCHASTIC INFLOW TURBULENCE SIMULATOR (Version 1.21)}

(Revised February 1, 2007)

\section{Background}

The TurbSim stochastic inflow turbulence code was developed to provide a numerical simulation of a full-field flow that contains bursts of coherent turbulence (organized turbulent structures in the flow that have a well-defined spatial relationship) that reflect the proper spatiotemporal turbulent velocity field relationships seen in instabilities associated with nocturnal boundary layer flows. Such features are not simulated well by the International Electrotechnical Commission (IEC) Normal Turbulence Models (NTMs). Its purpose is to provide the wind turbine designer with the ability to drive design code (FAST, MSC.ADAMS ${ }^{\circledR}$, or YawDyn) simulations of advanced turbine designs with simulated inflow turbulence environments that incorporate many of the important fluid dynamic features known to adversely affect turbine aeroelastic response and loading. The purpose of this document is to provide the user with a generalized overview of how the code has been developed and some of the theory behind that development. The details for the use of the TurbSim code are provided in the TurbSim User's Guide [1].

\section{The TurbSim Code}

The TurbSim code supports all of the features found in the previous SNLWIND-3D [2] and $S N$ wind inflow turbulence simulator codes that had their roots in Paul Veers' original stochastic wind simulator, SNLWIND [3]. All of the spectral models available in SNLWIND-3D [SMOOTH (flows over flat, homogeneous terrain), WF_UPW, WF_07D, and WF_14D (flows upwind of a multi-row wind farm and with 7 and 14 rotor diameter row-to-row spacing within the farm)] as well as the IEC Kaimal and von Karman NTMs that are provided in SNwind are included. The wind farm spectral models (WF_ $x x x$ ) were originally developed to mimic conditions seen upwind and at two row-to-row separations within a large, multi-row wind farm at San Gorgonio Pass in California. They have been validated up to a height of $50 \mathrm{~m}$ above ground level.

\section{NWTCUP Spectral Model}

TurbSim Version 1.01 and later versions include the NWTCUP (National Wind Technology Center UPwind) spectral model. This model generates a turbulent inflow that is characteristic of the highly turbulent conditions experienced when testing turbines at National Renewable Energy Laboratory's National Wind Technology Center (NWTC); i.e., downwind of a major mountain range. The NWTCUP model was validated using measurements from the upwind planar sonic anemometer array and response of the NWTC Advanced Research Turbine (ART) employed as part of the NWTC component of the Long-term Inflow and Structural Testing (LIST) Experiment [6]. It represents a test environment corresponding to those found in complex terrain situations that often 
present challenges for turbine operations. The NWTCUP model incorporates additional scaling features to better reflect conditions seen at the NWTC (high turbulence intensities and intense coherent turbulent structures encountered during stable, nighttime flows). In earlier versions of the code, the NWTCUP model utilized the low-frequency (longperiod) turbulent spectral model derived from measurements in San Gorgonio Pass, California [2] that did not fully reflect conditions seen at the NWTC. However, with the release of version 1.20, TurbSim incorporates NWTC spectral scaling derived from measurements taken from a planar sonic anemometer array that was part of the NWTC LIST experiment.

\section{GP_LLJ Spectral Model}

With the release of Version 1.10, a new model GP_LLJ (Great Plains Low-Level Jet) is included that simulates flow conditions associated with the large vertical shears and coherent turbulence encountered within and beneath Great Plains low-level jet streams. A low-level jet stream (LLJ) is a current of higher speed air that usually forms at night near the ground and is characterized by strong vertical wind shear beneath a wind speed maximum that typically occurs at heights between 50 and $500 \mathrm{~m}$ above ground level (AGL). Figure 1 shows an example of a LLJ as a series of vertical wind profiles observed 10-minutes apart between 02:40 and 04:00 LST in Southeast Colorado. The lower pair of horizontal dashed lines outline the height range of a $1.5 \mathrm{MW}$ turbine rotor while the upper two lines depict the expected rotor depth of a future onshore $10 \mathrm{MW}$ turbine.

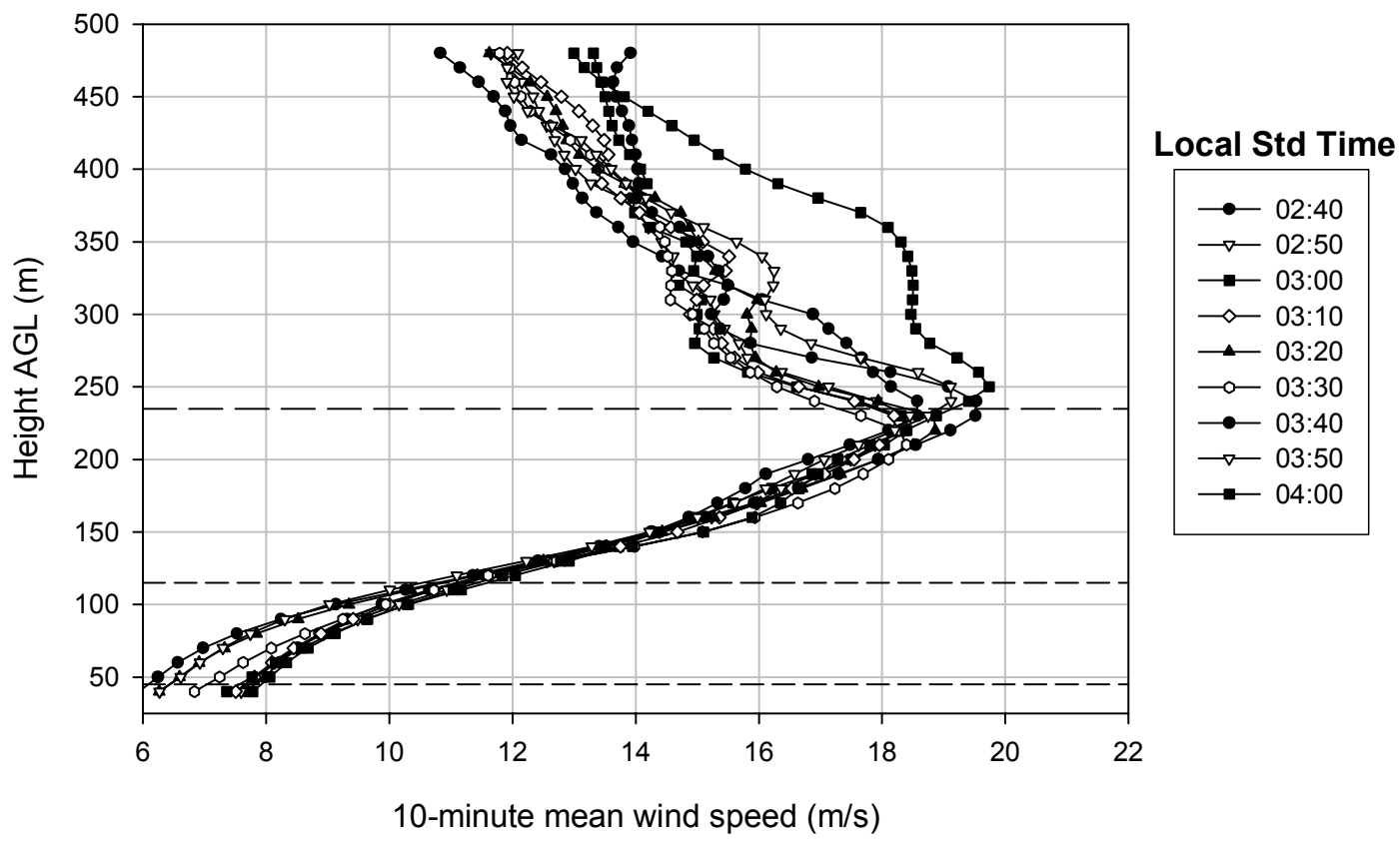

Figure 1. LLJ example.

The GP_LLJ model reflects conditions seen over the Great Plains with and without the presence of a low-level jet stream that occurs at a height between 70 and $490 \mathrm{~m}$ AGL. 
Local turbulence scaling and low-level jet vertical wind profiles used with the GP_LLJ model have been derived from measurements collected on a $120-\mathrm{m}$ tower and with a medium range Doppler acoustic wind profiler (SODAR) located in the southwestern Great Plains near Lamar, Colorado [4]. The GP_LLJ model allows the user to specify the jet height and peak wind speed (intensity) or to let the code randomly choose a jet height and/or wind speed based on the other specified boundary conditions.

The GP_LLJ model produces both wind speed and direction profiles that can be extended down to a height of $3 \mathrm{~m}$ AGL when the JET profile option is chosen. It is not possible to specify a shear exponent to describe a power law variation in wind speed across the specified rotor disk when using the JET option as the shape of the jet profiles are determined by the boundary conditions provided. The summary file generated for each simulation does contain an equivalent power law exponent across the rotor disk however. Requesting the LOG profile option when using the GP_LLJ model generates a simulation with a logarithmically varying vertical wind speed profile over a user-specified height range which can begin as low as $3 \mathrm{~m}$ AGL.

\section{Coherent Turbulent Structures}

The TurbSim code provides the ability to efficiently generate randomized coherent turbulent structures that are superimposed on the more random background turbulent field as produced by one of the diabatic (non-neutral) spectral models; i.e., SMOOTH, WF_UPW, WF_07D, WF_14D, NWTCUP, or GP_LLJ. Typically the size of the structures have a higher probability of being scaled to the dimensions of the requested rotor diameter but the user may request the placement of the coherent disturbance in either the upper or lower half of the specified rotor disk for rotor diameters of $30 \mathrm{~m}$ or larger. The presence of superimposed coherent structures can induce transient loading events on simulated turbine rotors and supporting structures $[4,5]$. The simulation of such structures is not adequately provided for in the inflow simulators up to now because of basic limitations in the mathematical procedures used. This combination of techniques, i.e., Fourier inversion plus time-domain Poisson and lognormal modeled events, produces the highly non-Gaussian flow behavior associated with the presence of coherent structures in actual flows.

The impact of coherent turbulent structures on wind turbine operations is discussed in [5]. The process of generating coherent turbulent structures involves first generating a background turbulent field using one of the diabatic spectral models listed above. The SMOOTH spectral model is generally recommended for conditions seen in homogeneous terrain when no low-level jets are expected. It can be considered a "reference" to which load simulations using the other spectral models can be compared. It can also be adjusted to meet measured scaling information which is sometimes useful. The NWTCUP spectral model is suggested for complex terrain applications, and the GP_LLJ spectral model is recommended for use in the Great Plains where low-level jets are frequent. As previously discussed, the GP_LLJ model has been based on observations in the southwestern Great Plains. The code also allows the user to use available observed turbulence information to improve the agreement in specific locations. 
The coherent turbulent structures exhibit the correct temporal and spatial phase relationships associated with the flow elements of the breakdown of a Kelvin-Helmholtz $(\mathrm{KH})$ wave or billow that have been derived from both Large-Eddy and Direct Numerical Simulations (LES and DNS). KH instability (KHI) is known to be more or less ubiquitous in the stable, nocturnal boundary layer. A more complete discussion of KHI and its impact on wind turbines is available in Sections 1-3 of [4] and in [5]. The coherent structures generated are then superimposed on the more random background similar to what occurs in natural flows.

Modeled as a combination of non-homogenous Poisson and lognormal stochastic processes, the randomized scaling of the coherent structures in this version of TurbSim is based on measurements taken from the anemometer array upwind of the NWTC ART Turbine as part of the LIST program [4,6]. A flow chart of the TurbSim code is shown in Figure 2. When the GP_LLJ model is specified, the scaling is based on measurements derived from the Lamar 120-m tower used as part of the Lamar Low-Level Jet Project (LLLJP) and any systematic differences based on that location and height above the ground are accounted for.

Every effort has been made to randomize the occurrence and scaling of coherent event structures that occur in natural, nocturnal boundary layer flows. If a flow containing coherent turbulent elements is desired, it is highly recommended that an ensemble of simulations using the same boundary conditions with a varying random seed be generated and the resulting statistics evaluated. Ideally, each of these individual flow realizations should be employed to drive the target wind turbine simulation, and the resulting aeroelastic response statistics should be compared in order to obtain some feel of the expected variability. A PERL-script to compute an ensemble of inflow realizations for a given set of boundary conditions is included in the distribution.

If coherent turbulence is requested and the specified gradient Richardson number (vertical dynamic stability) is greater than $\mathbf{- 0 . 0 5}$, a series of coherent disturbances are generated with random properties. This option should always be requested when using the NWTCUP model. Observations of low-level jets in the high plains of Southeast Colorado have revealed that coherent structures may or may not be present so the user may choose not to request them to simulate such situations when using the GP_LLJ model. The properties of the coherent structures include the number of disturbances, time of occurrence in the simulated record, and intensity. They are empirically scaled by the hub-height mean wind speed (or height of the center of the disturbance requested in the upper or lower half of the disk), the gradient Richardson number stability parameter, and the hub-height standard deviation of the vertical wind component $\left(\sigma_{w}\right)$ derived from the simulated background turbulence field.

The incorporation of the discrete coherent events requires the storage of about $270 \mathrm{MB}$ in addition to the TurbSim executable and associated support files. The coherent events are separate from the normal TurbSim archive. The use of the coherent events does require a bit more execution time in the AeroDyn program (where they are superimposed on the background turbulence) with the exact amount of time dependent on the number of events and their lengths called for in each realization that are, in turn, a function of the 
specified boundary conditions. The Cholesky factorization algorithm in TurbSim has been updated, and other parts of the code have been rewritten to be more efficient in terms of both CPU and memory usage.

\section{The KHTEST Function}

The ability to test the effects of intense coherent turbulent structures has been incorporated within TurbSim. Specifying "KHTEST" in the turbulence characteristic field generates a single intense disturbance in the center of a time series, without the random properties otherwise employed when coherent turbulence is requested. This test option overrides the Richardson number stability criterion and wind shear of the background turbulence field. It is available with only the NWTCUP spectral model. One use is to compare turbine simulations that have been excited with one of the IEC NTM models in order to assess the effects of intense coherent turbulence.

\section{Random Number Generators (RNGs)}

As opposed to the previous simulators in which only one random number generator (RNG) was provided, TurbSim allows the user a choice of one of three RNGs. A specification of "RNSNLW" in the input file invokes the original Sandia RNG that is used with $S N L W I N D$ and $S N L W I N D-3 D$. Adding a second seed value in place of the "RNSNLW" character string invokes an intrinsic Multiple Linear Congruential Generator (MLCG and used with SNwind), or substituting the character string "RANLUX" invokes level 3 of the Lüscher "Luxury Pseudorandom Numbers" RNG (see the TurbSim User's Guide [1] for additional information). After an extensive testing of these three generators, we recommend the use of RANLUX.

\section{TurbSim Applicability}

With a limited comparison of simulated results with measurements between 50 and 120 $\mathrm{m}$ from the NWTC LIST and Lamar 120-m towers, we believe the NWTCUP model is applicable up to heights of 100-120 m. We have extrapolated the vertical scaling measured on the Lamar 120-m tower and believe the GP_LLJ model is applicable up to a height of $230 \mathrm{~m}$ AGL based on limited SODAR observations. In the future, we plan to further evaluate the model simulation in the 120-230 m height range using data available from a wind profiling Doppler LIDAR. The wind farm related models, WF_xxx, are generally assumed to be applicable up to a height of $50 \mathrm{~m}$. The SMOOTH model is considered to be applicable in the lower portion of the atmospheric boundary layer (the surface layer), in which the vertical flux of momentum can be considered constant with height. The upper limit of this layer is generally considered to be the order of $100 \mathrm{~m}$ when no low-level jets are expected.

\section{TurbSim Applications}

TurbSim is intended to generate a series of inflow simulations based on a given set of initial boundary conditions that are employed with the design codes (FAST, MSC.ADAMS ${ }^{\circledR}$, or YawDyn) to produce response (load) solutions that can be analyzed 
using ensemble statistics. For example, at least nine stochastic degrees of freedom have been incorporated into the NWTCUP model and twelve in the GP_LLJ in order to provide a measure of the range of variation seen in actual flows. $\bar{A}$ minimum of 31 realizations is recommended for a specific set of boundary conditions to allow the use of large sample statistics to be employed properly.

If the objective is to evaluate the impacts of coherent turbulence on the structural response of a particular wind turbine design, there are several considerations that must be addressed. Our research has shown in [5] that coherent turbulence primarily drives the higher order modal responses as transport or flux of turbulent kinetic energy into the turbine structure where it must be dissipated. In order to assess such an impact, the turbine design code being used must provide sufficient fidelity to encompass a range of modal frequencies that fully describe the turbulence-induced harmonic vibrations. Thus the design code being employed must include a sufficient number of degrees of freedom to properly model this flux of energy.

In order for the FAST Code to accomplish simulations in a minimum amount of time, it supports only a relatively few degrees of freedom (currently 24). For a somewhat small and stiff turbine structure such as the NWTC ART we have found them to be sufficient (assuming the model has been "tuned" by actual field measurements). However for larger and more flexible designs such as the fictitious WindPACT 1.5 MW reference turbine or even larger turbines, many more degrees of freedom are required to fully simulate and evaluate the response to coherent turbulence excitation. Thus if the objective is to evaluate the impact of operating a large and flexible turbine design in coherent turbulence, the use of a multi-body design code which supports a large number of degrees of freedom (300-400 or more) such as MSC.ADAMS $\AA$ is generally required. This capability is necessary to fully appreciate the differences in response between the IEC NTM and KHTEST excitations.

\section{References}

1. Jonkman, B.J.; Buhl, M.L., Jr. (March 2007). “TurbSim User's Guide.” (Version 1.21) NREL/TP-500-41136. Golden, CO: National Renewable Energy Laboratory.

2. Kelley, N.D. (1992). "Full Vector (3-D) Inflow Simulation in Natural and Wind Farm Environments Using an Expanded Version of the SNLWIND (Veers) Turbulence Code." NREL/TP-442-5225. Golden, CO: National Renewable Energy Laboratory.

3. Veers, P.S. (March 1988). Three-Dimensional Wind Simulation, SAND88-0152. Albuquerque, NM: Sandia National Laboratories.

4. Kelley, N.; Shirazi, M.; Jager, D., Wilde, S.; Adams, J.; Buhl, M.; Sullivan, P., Patton, E. (January 2004). Lamar Low-Level Jet Project - Interim Report, NREL/TP500-34593. Golden, CO: National Renewable Energy Laboratory.

5. Kelley, N. D., Jonkman, B.J., Scott, G.N. (August 2005) “The Impact of Coherent Turbulence on Wind Turbine Aeroelastic Response and Its Simulation." NREL/CP500-38074. Golden, CO: National Renewable Energy Laboratory. 
6. Kelley, N.; Hand, M.; Larwood, S.; McKenna, E. (January 2002). "The NREL LargeScale Turbine Inflow and Response Experiment - Preliminary Results.” NREL/CP500-30917. Golden, CO: National Renewable Energy Laboratory. 


\section{List of Abbreviations}

AGL

ART

CS

DNS

GP LLJ

IEC

$\mathrm{KH}$

KHI

KHTEST

LIST

LLJ

LLLJP

LES

LIDAR

LST

MLCG

NTM

NWTC

NWTCUP

RNG

SODAR

WindPACT above ground level

Advanced Research Turbine

coherent structure

Direct Numerical Simulation

Great Plains Low-Level Jet spectral model

International Electrotechnical Commission

Kelvin-Helmholtz

Kelvin-Helmholtz Instability

Kelvin-Helmholtz Billow Test Function

Long-Term Inflow and Structural Testing

low-level jet stream

Lamar Low-Level Jet Project

Large-Eddy Simulation

wind profiler utilizing LIght Detection And Ranging

local standard time

multiple linear congruential random number generator

Normal Turbulence Model

National Wind Technology Center

NWTC UPwind spectral model

random number generator

vertical wind profiler utilizing SOund Detection And Ranging

fictitious 1.5 MW reference turbine design 


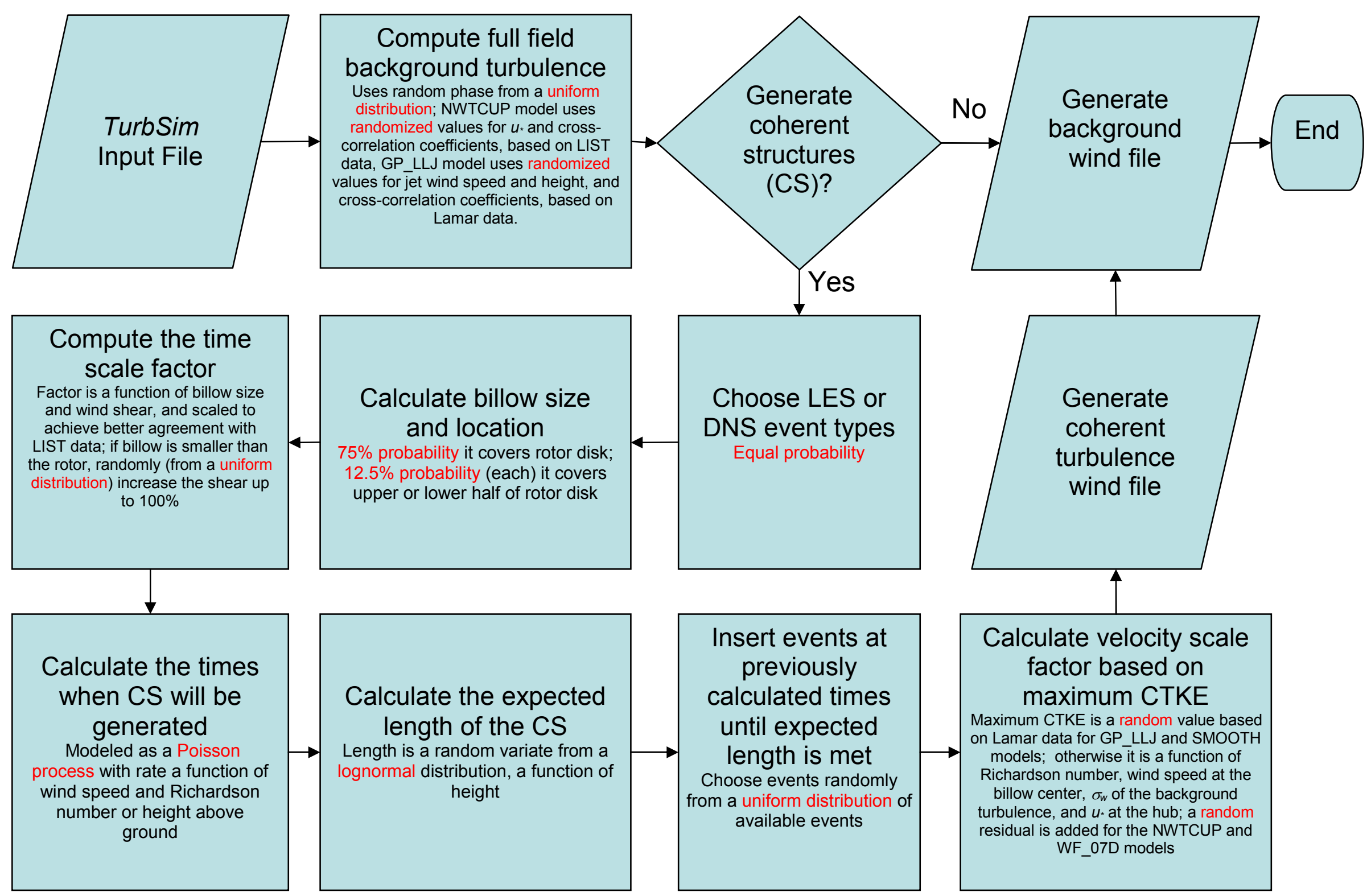

Figure 2. TurbSim Flowchart 


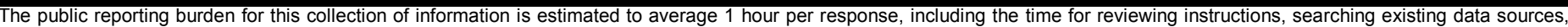

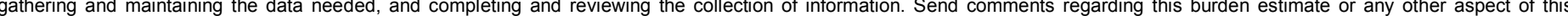

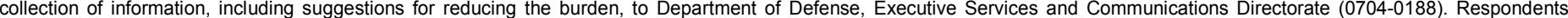

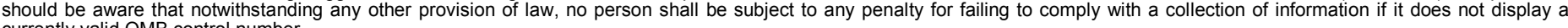
currently valid OMB control number.

PLEASE DO NOT RETURN YOUR FORM TO THE ABOVE ORGANIZATION

\section{REPORT DATE (DD-MM-YYYY) \\ April 2007}

4. TITLE AND SUBTITLE

Overview of the TurbSim Stochastic Inflow Turbulence Simulator:

Version 1.21 (Revised February 1, 2001)
3. DATES COVERED (From - To)

5a. CONTRACT NUMBER

DE-AC36-99-GO10337

5b. GRANT NUMBER

5c. PROGRAM ELEMENT NUMBER

5d. PROJECT NUMBER

NREL/TP-500-41137

5e. TASK NUMBER

WER7.2501

5f. WORK UNIT NUMBER

7. PERFORMING ORGANIZATION NAME(S) AND ADDRESS(ES)

National Renewable Energy Laboratory

1617 Cole Blvd.

REPORT NUMBER

Golden, CO 80401-3393

NREL/TP-500-41137

9. SPONSORING/MONITORING AGENCY NAME(S) AND ADDRESS(ES)

10. SPONSOR/MONITOR'S ACRONYM(S) NREL

11. SPONSORING/MONITORING AGENCY REPORT NUMBER

\section{DISTRIBUTION AVAILABILITY STATEMENT}

National Technical Information Service

U.S. Department of Commerce

5285 Port Royal Road

Springfield, VA 22161

\section{SUPPLEMENTARY NOTES}

\section{ABSTRACT (Maximum 200 Words)}

The TurbSim stochastic inflow turbulence code was developed to provide a numerical simulation of a full-field flow that contains coherent turbulence structures that reflect the proper spatiotemporal turbulent velocity field relationships seen in instabilities associated with nocturnal boundary layer flows. This report provides the user with an overview of how the TurbSim code has been developed and some of the theory behind that development.

\section{SUBJECT TERMS}

Turbulence simulation; TurbSim stochastic inflow turbulence code; design codes; wind turbine design

\begin{tabular}{l}
\hline \multicolumn{3}{|l|}{ 16. SECURITY CLASSIFICATION OF: } \\
\hline \begin{tabular}{l|l|l|} 
a. REPORT & b. ABSTRACT & c. THIS PAGE \\
Unclassified & Unclassified & Unclassified \\
\hline
\end{tabular} \\
\hline
\end{tabular}

17. LIMITATION
OF ABSTRACT
UL

18. NUMBER
OF PAGES

19a. NAME OF RESPONSIBLE PERSON

19b. TELEPONE NUMBER (Include area code) 